\title{
Functional Analysis of c-Myb Protein in T-Lymphocytic Cell Lines Shows that It trans-Activates the c-myc Promoter
}

\author{
JANET L. EVANS,${ }^{1 \dagger}$ TERRY L. MOORE, ${ }^{1}$ W. MICHAEL KUEHL,${ }^{2}$ TIMOTHY BENDER,${ }^{3}$ \\ AND JENNY PAN-YUN TING ${ }^{1 *}$

\begin{abstract}
Lineberger Cancer Research Center, Department of Microbiology-Immunology, University of North Carolina, Chapel Hill, North Carolina 27599-7295'; Department of Microbiology-Immunology, University of Virginia, Charlottesville, Virginia 229033 ; and Navy Medical Oncology, National Cancer Institute, Bethesda, Maryland 20892 ${ }^{2}$
\end{abstract}

Received 11 January 1990/Accepted 8 August 1990

\begin{abstract}
The function of $\mathrm{c}-\mathrm{Myb}$ protein was revealed by transfecting an expression vector containing the entire c-Myb protein-coding sequence into the murine CTLL-2 T-cell line. Expressions of high levels of c-Myb protein did not alter the expression of several T-cell markers, c-fos mRNA expression, responses to interleukin-2, and growth characteristics of these cells. Interestingly, expression of the c-myc gene was drastically increased in this clone. Further, the c-myb expression plasmid, but not a frameshift mutant of $c-m y b$, enhanced the expression of a hybrid construct of $\mathrm{c}-\mathrm{myc}$ promoter linked to a reporter gene by 8- to 14-fold. These results demonstrate a role of c-Myb protein in c-myc gene expression.
\end{abstract}

The c-myb proto-oncogene is the cellular homolog of the transforming $v-m y b$ gene of avian myeloblastosis virus, which causes acute myelomonocytic leukemia in chickens and transformation of myeloid cells in vitro $(22,29)$. The gene is mainly expressed by immature hematopoietic cells. The c-myb gene encodes a 75-kilodalton nuclear protein that is associated with the nuclear matrix and exhibits DNAbinding activity $(3,5,25,28,31)$. Its viral counterpart, the $\mathrm{v}$-Myb protein, has an affinity for the sequence pyAACG/TT (4). However, the function of both proteins remains unclear. Existing reports in the literature point to three potential roles for the c-myb protein: gene regulation, cell differentiation, and proliferation.

The c-myb gene was initially proposed to be involved in gene regulation owing to its nuclear location and its ability to bind DNA $(5,28,31)$. Antiserum directed against a portion of the c-Myb protein is known to inhibit mRNA transcription in ML-1 human myeloblastic leukemia cells (24). During the preparation of this manuscript, several groups have shown by transient cotransfection experiments that c-Myb transactivates promoter function. These target promoters include multiple copies of the simian virus 40 (SV40) enhancer (38), an artificial promoter of multiple copies of pyAAC $(\mathrm{G} / \mathrm{T}) \mathrm{G}$ (54), and the hsp70 promoter (29). These results strongly suggest a transcriptional role for $\mathrm{c}-\mathrm{Myb}$; however, the cellular target genes of $\mathrm{c}-\mathrm{Myb}$ in lymphocytes have not been identified.

The c-Myb protein is proposed to be important in differentiation because of its differential patterns of expression in immature and mature differentiated cells $(43,50)$. Elevated expression of a transfected c-myb gene in murine erythroleukemia cells blocks differentiation normally induced by dimethyl sulfoxide (7). An antisense oligonucleotide targeted at the c-myb transcript also interferes with in vitro hematopoiesis (19).

Finally, another proposed role for c-Myb is the control of cell proliferation. Expression of $c-m y b$ in T cells is regulated

\footnotetext{
* Corresponding author.

$\dagger$ Present address: Becton-Dickinson Immunocytometry Systems, San Jose, CA 94566. Submitted in partial fulfillment of a Doctorate in Philosophy degree.
}

in a cell-cycle-dependent manner and may be linked to stimulation via ligand-receptor interactions $(33,46,49,50$, 51). Cells treated with interleukin-2 (IL-2) or mitogen express high levels of $c-m y b$ during cell cycle progression and prior to proliferation $(40,49)$.

Abnormal expression of c-myb, due to either rearrangement or amplification of the gene, has been observed in a number of different neoplasias $(2,37,44,47,52)$. In addition, elevated expression of the c-myb gene also occurs in an aberrant $\mathrm{CD}^{-}{ }^{-} \mathrm{CD} 8^{-} \mathrm{T}$-cell population which accumulates in the lymph nodes of autoimmune $l p r$ mice $(16,36,56)$. It has been suggested that the aberrant $l p r \mathrm{~T}$ cells resulted from a defect in thymocyte maturation (56), and the high c-myb expression is likely to be associated with abnormal T-cell ontogeny (36).

Due to the crucial roles c-myb may assume, this report examines the effects of elevated c-myb expression in $\mathrm{T}$ lymphocytes. Our findings showed that the $\mathrm{c}-\mathrm{Myb}$ protein can trans-activate the c-myc promoter. These results provide strong evidence that c-Myb protein regulates the promoter function of c-myc in T-cell lines.

\section{MATERIALS AND METHODS}

Cells. The IL-2-dependent CTLL-2 T-cell line (20) was obtained from the American Type Culture Collection (Rockville, Md.) and cultured in Dulbecco modified Eagle medium supplemented with $10 \%$ fetal bovine serum and containing either 5\% supernatant from phorbol-12-myristate-13-acetatestimulated EL-4 cells (17) or a recombinant IL-2 (Amgen, Thousand Oaks, Calif.). EL-4 is a murine thymoma cell line.

Expression vectors and probes. The pRmb3SVneo expression vector contains a mouse c-myb cDNA promoted from the Rous sarcoma virus long terminal repeat (Fig. 1). The plasmid also contains the SV40 promoter link to the neomycin gene (derived from pSV2neo), which encodes resistance to the antibiotic G418. The pSV2neo plasmid (48) contains the SV40 promoter link to the neomycin gene. pM(Bg)CAT contains a 1.7-kilobase (kb) $B g l \mathrm{II}-\mathrm{Bg} / \mathrm{II}$ fragment of the murine c-myc 5 -flanking DNA, exon 1 , and a portion of the intron 1 link to the chloramphenical acetyltransferase (CAT) gene (cat) (41). pCAT $(\triangle E P)$ is the parent plasmid of $\mathrm{pM}(\mathrm{Bg})$ CAT, and it does not have any c-myc sequences. pSV2CAT 

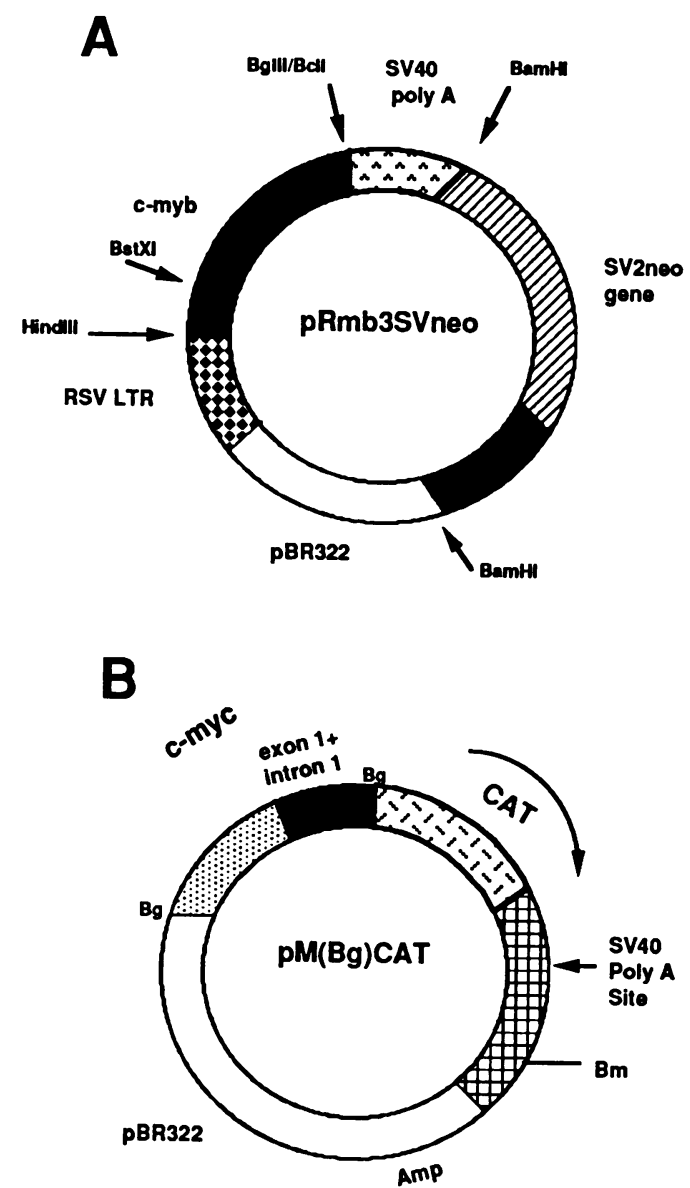

FIG. 1. Structures of the pRmb3SVneo (A) expression plasmid and the $\mathrm{pM}(\mathrm{Bg}) \mathrm{CAT}$ hybrid plasmid (B). The $\mathrm{pRmb3SVneo} \mathrm{vector}$ contains a Rous sarcoma virus long terminal repeat which promotes transcription of the SmaI-BglII fragment of the entire murine c-myb coding region. The $\mathrm{SV} 40$ promoter was used to drive transcription of the neomycin gene and is derived from the pSV2neo expression vector (48). In $\mathrm{pM}(\mathrm{Bg}) \mathrm{CAT}$, a 1.7-kb BglII (Bg) fragment containing the c-myc 5'-flanking sequence, exon 1 , and a portion of intron 1 was inserted $5^{\prime}$ of the cat gene in $\mathrm{pCAT}(\Delta \mathrm{EP})(41)$.

contains the SV40 enhancer-early promoter region linked to the cat gene (24). pA10CAT contains the SV40 early promoter linked to the cat gene. Recombinant plasmids containing c-myc (1) and v-fos (11) and mouse gamma-actin probe pHF-1 (23) have been described previously. pJTmyb-fs is a frameshift mutant of pRmb3SVneo. It was produced by linearization of pRmb3SVneo with Bst XI, digestion with mung bean nuclease, ligation, and transformation into Escherichia coli $\mathrm{H} 5$. The resultant plasmid was characterized by double-stranded DNA sequence determination. The Bst XI site CCATATTTCTGG was mutated to CCAGG with a 7-base-pair deletion.

Antibodies. Anti-CD8 (53-6.7) (32), anti-CD4 (RL 172.4) (13), anti-Thy-1.2 (AT83) (32), RA3-3A1 (9), RA3-2C2 (8), 9F3 (15), 6C3 (14), anti-IL-2 receptor (34), and anti-CD3 hamster monoclonal antibody $(145-2 \mathrm{C} 11)$ have been described. The rabbit anti-c-Myb polyclonal antiserum (5) was obtained from William J. Boyle, Salk Institute, San Diego, Calif.

Fluorescence staining and flow cytometric analysis. Fluorescence staining and flow cytometric analysis were performed as described previously (56).
Labeling of cells and immunoprecipitations. Cells were prepared and lysates were immunoprecipitated as previously described (16).

Transfection of CTLL-2 cells and selection with G418. CTLL-2 cells $\left(1 \times 10^{7}\right)$ were transfected by electroporation with a Bio-Rad gene pulser (45). After transfection, cells were allowed to recover for 2 days before selection in growth medium containing $2 \mathrm{mg}$ of the antibiotic G418 (10) (GIBCO Laboratories, Grand Island, N.Y.) per ml. Transfected cells were cloned by limiting dilution and were determined to be clones by calculating the percentage of wells containing cells growing in selective medium.

Preparation of crude cytoplasmic RNA and dot-blot hybridization. Cytoplasmic RNA was prepared and screened for levels of c-myb by dot-blot hybridization as described previously (55).

RNA isolation and Northern (RNA) hybridization. Total cellular RNA was prepared from selected clones and Northern hybridizations were performed as described previously (6).

Transient transfection and CAT assays. CTLL-2 and EL-4 cells were grown to the log phase and then transfected with various plasmids by using the Bio-Rad gene pulser electroporation apparatus as previously described $(21,45)$. CAT assays were performed as described previously (45). Percent acetylation was quantified by cutting out sections of the plate that corresponded to these two forms, followed by scintillation counting.

Determination of cell doubling times. Transfected clones were cultured in 24-well plates at $5 \times 10^{4}$ cells per well in 1 $\mathrm{ml}$ of growth medium containing 5 units of recombinant IL-2 per ml. Samples were removed every $24 \mathrm{~h}$, and cells were counted with a Coulter Counter (model ZM; Coulter Electronics Limited, Hialeah, Fla.). Cell doubling times were determined from graphs of cell number versus time.

\section{RESULTS}

Cells transfected with pRmb3SVneo express high levels of c-myb RNA. CTLL-2 cells were transfected by electroporation with either the pRmb3SVneo or pSV2neo expression vector shown in Fig. 1. After selection with the antibiotic G418, a cytoplasmic dot-blot was used to verify that pRmb3SVneo transfectants contained abundant c-mybspecific RNA (10).

The experimental and control transfectants were subsequently cloned by limiting dilution. Southern analyses were performed with DNA extracted from experimental and control transfectants to ensure that the clones were different. Finally, the clones were expanded and verified for expression of c-myb RNA, using dot-blot hybridization as the screening procedure.

pRmb3SVneo transfectants express c-myb gene product. To verify that the pRmb3SVneo-transfected clones produced c-myb mRNA, we subjected purified RNA from several pRmb3SVneo-transfected clones to Northern analysis. Two different $c-m y b$ transcripts were observed in all the pRmb3SVneo-transfected clones (Fig. 2). The larger transcript $(3.8 \mathrm{~kb})$ represents the c-myb message transcribed from the endogenous gene (44), and it is present in all samples. The smaller transcript $(2.8 \mathrm{~kb})$ was the correct size for the c-myb cDNA transcribed from the pRmb3SVneo expression vector which has eliminated $3^{\prime}$ untranslated sequence.

It was observed by one of us that $c-m y b$ transcripts derived from pRmb3SVneo were translated to various ex- 


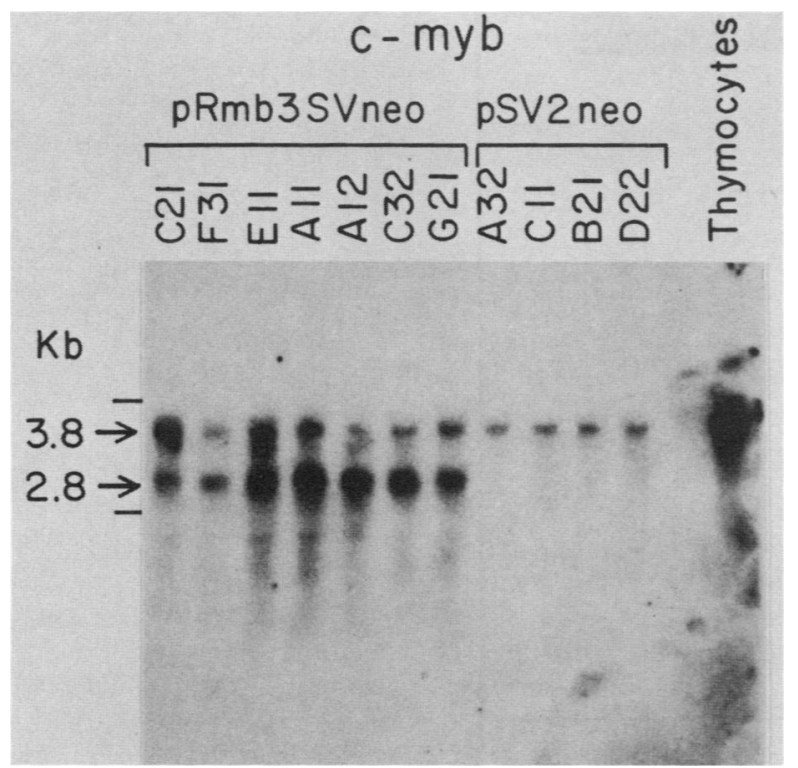

FIG. 2. Expression of c-myb transcripts by clones transfected with the pRmb3SVneo or pSV2neo plasmid and from normal thymocytes. RNA was size fractionated by agarose electrophoresis, bound to a nitrocellulose filter, and hybridized to the c-myb probe. The numbers indicate the sizes of the endogenous $c-m y b$ transcript and the $c-m y b$ mRNA transcribed from the $\mathrm{pRmb3Svneo}$ vector $\mathbf{3 . 8}$ and $2.8 \mathrm{~kb}$, respectively). Upper and lower bars represent locations of the $28 \mathrm{~S}$ and $18 \mathrm{~S}$ rRNA markers, respectively.

tents in transfected cells. Thus, it was critical to analyze all the transfected clones for $\mathrm{c}-\mathrm{Myb}$ protein levels. Immunoprecipitation with an anti-c-Myb antiserum showed that a pRmb3SVneo-transfected clone, E11, produced a higher level of c-Myb protein than all the other clones (Fig. 3). From densitometric scanning, the quantity of $\mathrm{c}-\mathrm{Myb}$ protein in E11 ranged from 8- to 108 -fold more than in various experimental and control clones. At this point, we cannot rule out the possibility that the c-Myb protein produced by E11 is derived from the endogenous c-myb transcript. Aside from E11, no consistent differences in C-Myb protein levels were observed between the other experimental and control samples.

Expression of c-myc proto-oncogene is increased in clone E11. A proposed role for the c-Myb protein is gene regulation. We examined the transfected clones for alterations in the expression of the c-myc and c-fos proto-oncogenes, two early competence genes that encode proteins which may play important roles in cell proliferation and transcription $(18,26,27,39,42,53)$. Baseline levels of c-myc were detected by Northern hybridization in all the clones examined (Fig. 4). However, clone E11 consistently expressed greatly enhanced levels of the 2.4-kb c-myc transcript. There were no detectable c-fos transcripts in any of the clones (data not shown). Since only one clone produced higher levels of the c-Myb protein, further investigations described below were necessary.

Stimulation of c-myc promoter by c-Myb protein. To further examine the proposed role of $\mathrm{c}-\mathrm{Myb}$ in $\mathrm{c}-m y c$ gene regulation, we cotransfected the murine T cell line EL-4 with the pRmb3SVneo expression vector and pM(Bg)CAT (a plasmid with the cat reporter gene under the control of the c-myc promoter [Fig. 1B] [also reference 41]). As a control, pM(Bg)

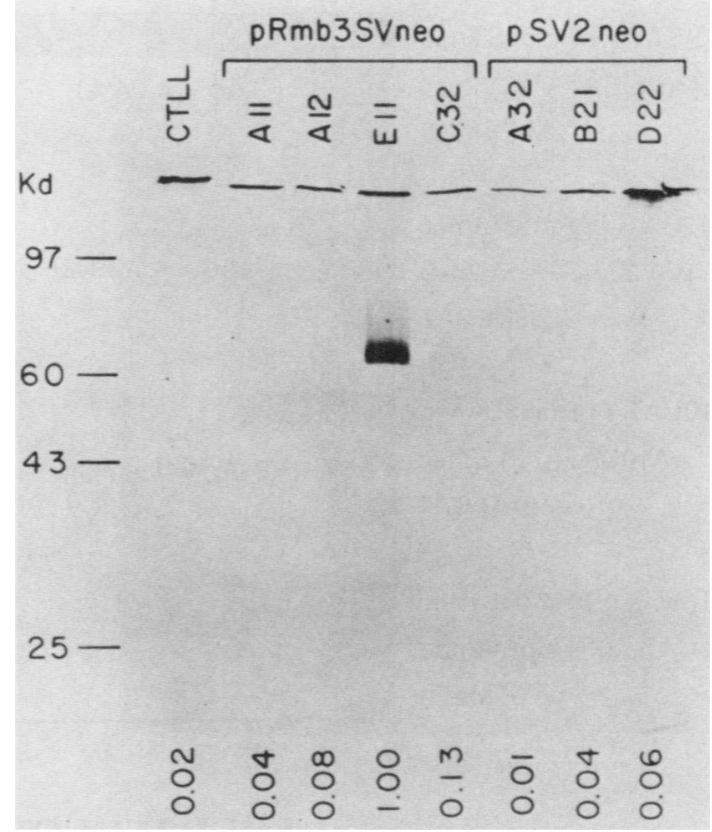

FIG. 3. Expression of c-Myb protein from CTLL-2 parent cells and from clones derived from pRmb3SVneo- or pSV2neo-transfected cells. Cells were metabolically labeled with $\left.{ }^{35} S\right]$ methionine, and cell lysates were prepared. The c-Myb protein was precipitated with the anti-c-Myb antiserum and analyzed on a sodium dodecyl sulfate-10\% polyacrylamide gel. Numbers to the left refer to the positions of molecular size markers (kd, kilodaltons). The Mybspecific antiserum detects a 75-kilodalton protein. Numbers below each lane represent amounts of c-Myb protein in each clone relative to that in clone E11 as determined by densitometric scanning.

CAT was cotransfected with pSV2neo (Fig. 5A). This control yielded a low level of CAT activity that was only slightly higher than that of pM(Bg)CAT alone. This slight enhancement is most likely due to carrier DNA effects. In the experimental group, cotransfection of $\mathrm{pM}(\mathrm{Bg}) \mathrm{CAT}$ and

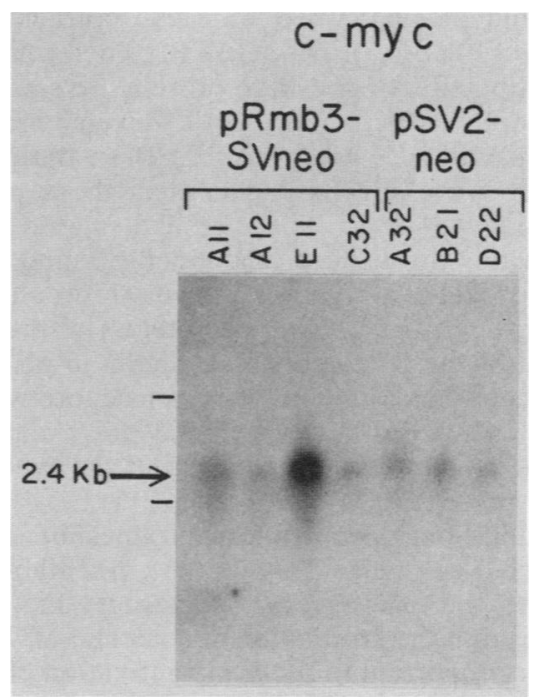

FIG. 4. Expression of the c-myc gene by transfectant clones. Purified RNA was size fractionated by agarose electrophoresis, bound to a nitrocellulose filter, and hybridized to the c-myc probe. The location of the 2.4-kb c-myc transcript is indicated. Upper and lower bars represent the $28 \mathrm{~S}$ and $18 \mathrm{~S}$ rRNA markers, respectively. 


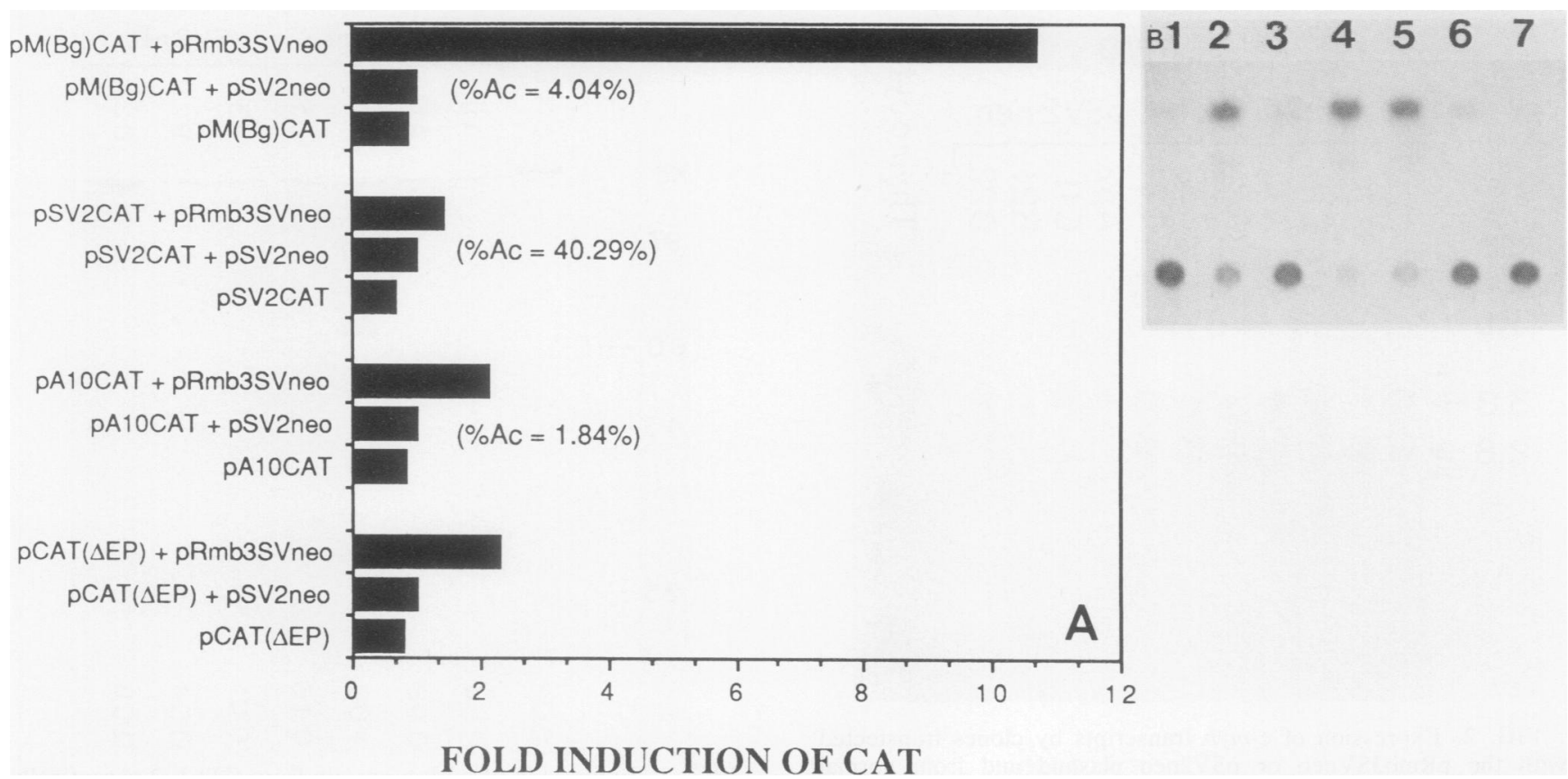

FIG. 5. (A) The trans-activation of the c-myc promoter by the c-Myb protein. The various plasmids used to transfect or to cotransfect EL-4 cells are shown to the left of the graph. Fold induction was calculated by the following equation: \% acetylation of experimental cotransfection consisting of pRmb3SVneo plus the appropriate cat gene-containing construct/\% acetylation of control cotransfection consisting of pSV2neo plus the appropriate cat-containing construct. Percent acetylation (\%Ac) of individual control cotransfection is given in parentheses. This value is also expressed as 1 on the $x$ axis. Results from four representative experiments are averaged and shown above. Another seven experiments showed similar results; however, they lacked the pCAT( $\triangle E P$ ) control. (B) Frameshift mutant of pRmb3SVneo does not transactivate the c-myc promoter. EL-4 cells were transfected with the following plasmids: $\mathrm{pM}(\mathrm{Bg}) \mathrm{CAT}(\mathrm{lane} 1)$; pM(Bg)CAT plus pRmb3SVneo (lane 2); pM(BG)CAT plus pJTmyb-fs (lane 3); pSV2CAT plus pRmb3SVneo (lane 4); pSV2CAT plus pJTmyb-fs (lane 5); pCAT $(\Delta \mathrm{EP})$ plus pRmb3SVneo (lane 6); pCAT( $\triangle \mathrm{EP})$ plus pJTmyb-fs (lane 7).

pRmb3SVneo gave a 10.65 -fold induction of CAT activity over the control cotransfected group. The range of induction for 11 independent transfections was 8- to 14-fold. Notably, this high level of induction was reproducibly observed when the cells were in the log phase but not when they were in the stationary phase of the cell cycle.

The plasmid pRmb3SVneo was also cotransfected with pSV2CAT, pA10CAT, or pCAT $(\Delta \mathrm{EP})$ to determine whether the trans-acting effects of $\mathrm{c}-\mathrm{Myb}$ protein are specific for the c-myc promoter (Fig. 5A). CAT levels produced by pSV2CAT, pA10CAT, and $\operatorname{pCAT}(\triangle E P)$ in the presence of pRmb3SVneo were slightly higher than those produced in the presence of pSV2neo. These results suggest that c-Myb weakly activates through yet undefined plasmid sequences; however, the level of activation was very low compared with activation through the $c-m y c$ promoter. The presence of a single repeat of the SV40 enhancer region in pSV2CAT did not affect this basal activation. This is in accord with another report which showed that c-Myb did not trans-activate a single repeat of the SV40 enhancer but did when multiple copies were present (38).

As an additional control, a frameshift mutant of pRmb3SVneo was made. This mutant, pJTmyb-fs, did not trans-activate the pM(Bg)CAT construct (Fig. 5B). This demonstrates that the production of correct c-Myb transcript and protein is important in the trans-activation phenomenon described above.

The basic trend described above has been reproduced in CTLL-2 in two experiments and in another murine thymoma line, BW5147 (data not shown).

Elevated c-Myb protein did not alter responses to recombi- nant IL-2, doubling time, or cell surface phenotypes. Transfected clones were tested for their ability to proliferate to recombinant IL-2, their doubling time, and surface phenotypes (data not shown). First, there were slight variations in the proliferative capacities of various clones for a range of IL-2; however E11 and the other clones were indistinguishable in their ability to respond to IL-2 and their dependency on IL-2. Second, all the clones including E11 exhibited similar doubling times ranging from 10 to $12 \mathrm{~h}$. Finally, all the clones including E11 expressed indistinguishable levels of differentiation markers, as determined by immunocytofluorometry. These include Thy-1, CD4, CD8, IL-2 receptor, and T3. Markers that are expressed by $l p r \mathrm{~T}$ cells which are detectable by antibodies RA3-3A1, RA3-2C2, 9F3, and 6C3 were also indistinguishable on E11 versus the other clones.

\section{DISCUSSION}

In this study, the c-myb gene was introduced into a T-cell line to examine directly its function in T cells. The effects of elevated c-Myb protein on the expression of genes proposed to be involved in cell proliferation and activation, on the expression of differentiation markers, on proliferation, and on cell cycle doubling time were determined.

The presumption for examining c-myc is that the myriad roles attributed to c-Myb may be due to its ability to regulate other genes which in turn are critical for cell proliferation, differentiation, or hematopoiesis. In accord with this hypothesis, this analysis showed that a clone which expresses high levels of c-Myb protein also expresses corollary increases in c-myc transcripts. Additional cotransfection experiments 
showed that c-Myb trans-activates $1.7 \mathrm{~kb}$ of the c-myc promoter. It is noteworthy that this region of the $c-m y c$ promoter contains one copy of the $\mathrm{v}$-Myb recognition site, pyAAC(G/T)T. Future site-specific mutagenesis of the consensus $v-m y b$ recognition sequence within the c-myc promoter should determine whether this sequence is indeed important for regulation by the c-Myb protein.

It is noteworthy that the c-Myc protein may also regulate gene expression, as demonstrated by the ability of the c-Myc protein to enhance heterologous gene transcription $(27,39)$. It is possible that c-myc and c-myb are members of a cascade or cycle of regulatory genes and that $c-m y b$ has pleiotropic effects on the expression of multiple genes, thus serving as a master regulatory gene.

Contrary to our finding, Clarke et al. (7) observed that Friend murine erythroleukemia cells which constitutively expressed high levels of a transfected c-myb gene exhibited normal regulation and levels of $c-m y c$. It is very likely that the effects of c-Myb protein are cell type and differentiation dependent.

In contrast to c-myc, the expression of c-fos was not induced. This suggests that the increased c-myc expression by clone E11 was not due to a general increase in gene transcription nor to a global activation of regulatory oncogenes.

The analysis of c-myb-transfected CTLL-2 clones showed that despite the elevated levels of $c-m y b$ and subsequently c-myc, IL-2 dependency, as well as IL-2-dependent proliferation and cell cycling, have not been altered. In light of reports that support a role for $c-m y b$ and $c-m y c$ in cell proliferation, our findings imply several possibilities. First, it is likely that certain factors in addition to c-myb and c-myc are involved in the control of cell division. Second, the low levels of endogenous c- $m y b$ produced by the parent CTLL-2 line may be sufficient to mediate its role in cell proliferation and cell cycle progression. Third, due to the necessity to include IL-2 in these studies, it is possible that IL-2 overrides some of the effects of the transfected c-myb.

Elevated c-Myb protein also did not affect the expression of T-cell differentiation markers or induce the expression of surface markers typical of the abnormal $l p r$ T cells. The $l p r$ $\mathrm{T}$ cells produce high levels of $\mathrm{c}-\mathrm{Myb}$ protein, lack the CD4 and CD8 markers of normal mature $T$ cells, and express markers which are not found on normal peripheral $\mathrm{T}$ cells $(12,35)$. Our results showed that the presence of high c-Myb protein alone does not alter the expression of a panel of differentiation numbers.

In summary, our study showed that a high level of c-Myb protein in transfected CTLL-2 cells does not appear to affect cell proliferation or the rate of cell cycle progression. The surface phenotype of the clone which expressed elevated c-Myb protein was not different from those of clones which synthesized much lower levels of the protein. These data suggest that other factors are involved in addition to, or exclusive of, $\mathrm{c}-\mathrm{Myb}$ in the regulation of the above processes. In contrast, enhanced expression of the c-myb proto-oncogene is associated with high c-myc levels. This is the first demonstration of a c-Myb-mediated regulation of c-myc.

\section{ACKNOWLEDGMENTS}

We thank Ken Marcu for providing the pM(Bg)CAT and $\operatorname{pCAT}(\triangle E P)$ plasmids and William Boyle for providing the anti-cMyb reagent. We also thank Michael Bishop, Inder Verma, and Grace Shen-Ong for providing plasmid constructs and Jane Radford for secretarial and graphic assistance.

This work is supported by Public Health Service grants R01-48185 to J. P.-Y. Ting and P01 CA40042 to T. Bender from the National Institutes of Health.

\section{ADDENDUM IN PROOF}

A paper by S. A. Ness et al. (Cell 59:1115) shows that c-Myb trans-activates the Mim-1 gene.

\section{LITERATURE CITED}

1. Alitalo, K., M. Schwab, C. C. Lin, H. E. Varmus, and J. M. Bishop. 1983. Homogeneously staining chromosomal regions contain amplified copies of an abundantly expressed cellular oncogene $(c-m y c)$ in malignant neuroendocrine cells from a human. Proc. Natl. Acad. Sci. USA 80:1707-1711.

2. Alitalo, K., R. Winqvist, C. C. Lin, A. DeLa Chapelle, M. Schwab, and J. M. Bishop. 1984. Aberrant expression of an amplified c-myb oncogene in two cell lines from a colon carcinoma. Proc. Natl. Acad. Sci. USA 81:4534-4538.

3. Bading, H., J. Hansen, and K. Moelling. 1987. Selective DNA binding of the human cellular myb protein isolated by immunoaffinity chromatography using a monoclonal antibody. Oncogene 1:395-401.

4. Biedenkapp, H., U. Borgmeyer, A. E. Sippel, and K.-H. Klempnauer. 1988. Viral $m y b$ oncogene encodes a sequence-specific DNA-binding activity. Nature (London) 335:835-837.

5. Boyle, W. J., J. S. Lipsick, and M. A. Baluda. 1986. Antibodies to the evolutionarily conserved amino-terminal region of the $v$ - $m y b$-encoded protein detect the c-myb protein in widely divergent metazoan species. Proc. Natl. Acad. Sci. USA 83: 4685-4689.

6. Chirgwin, J. M., A. E. Przybyla, R. J. MacDonald, and W. J. Rutter. 1979. Isolation of biologically active ribonucleic acid from sources enriched in ribonuclease. Biochemistry 18:5294 5299.

7. Clarke, M. F., J. F. Kukowska-Latallo, E. Westin, M. Smith, and E. V. Prochownik. 1988. Constitutive expression of a c-myb cDNA blocks Friend murine erythroleukemia cell differentiation. Mol. Cell. Biol. 8:884-892.

8. Coffman, R. L., and I. L. Weissman. 1981. A monoclonal antibody that recognizes $B$ cells and B cell precursors in mice. J. Exp. Med. 153:269-279.

9. Coffman, R. L., and I. L. Weissman. 1981. B220: a B cellspecific member of the T200 glycoprotein family. Nature (London) 289:681-683.

10. Colbere-Garapin, F., F. Horodniceanu, P. Kourilsky, and A.-C. Garapin. 1981. A new dominant hybrid selective marker for higher eukaryotic cells. J. Mol. Biol. 150:1-14.

11. Curran, T., G. Peters, C. Van Beveren, N. M. Teich, and I. M. Verma. 1982. FBJ murine osteosarcoma virus: identification and molecular cloning of biologically active proviral DNA. J. Virol. 44:674-682.

12. Davignon, J. L., R. C. Budd, R. Ceredig, P. F. Piguet, H. R. MacDonald, J. C. Cerottini, P. Vassalli, and S. Izui. 1985. Functional analysis of $\mathrm{T}$ cell subsets from mice bearing the $l p r$ gene. J. Immunol. 135:2423-2428.

13. Dialynas, D. P., D. B. Wilde, P. Marrack, A. Pierres, K. A. Wall, W. Havran, G. Otten, M. R. Loken, M. Pierres, J. Kappler, and F. W. Fitch. 1983. Characterization of the murine antigenic determinant, designated L3T4a, recognized by monoclonal antibody GK1.5: expression of L3T4a by functional T cell clones appears to correlate primarily with class II MHC antigenreactivity. Immunol. Rev. 74:29-56.

14. Dumont, F. J., L. Z. Coker, R. C. Habbersett, and J. A. Treffinger. 1985. Xenogenic monoclonal antibody to an Ly-6linked murine cell surface antigen: differential reactivity with $T$ cell subpopulations and bone marrow cells. J. Immunol. 134: 2357-2365.

15. Dumont, F. J., R. C. Habbersett, and E. A. Nichols. 1984. A new lymphocyte surface antigen defined by a monoclonal antibody (9F3) to the T cell population expanding in MRL/Mp-lpr/lpr mice.' J. Immunol. 133:809-815.

16. Evans, J. L., W. J. Boyle, and J. P.-Y. Ting. 1987. Molecular basis of elevated c-myb expression in the abnormal $\mathrm{L}^{3} \mathrm{~T}^{-}$, 
Lyt-2 ${ }^{-}$T lymphocytes of autoimmune mice. J. Immunol. 139: 3497-3505.

17. Farrar, J. J., M. Howard, J. Fuller-Farrar, and W. E. Paul. 1983. Biochemical and physicochemical characterization of mouse B cell growth factor: a lymphokine distinct from interleukin 2. J. Immunol. 131:1838-1842.

18. Gentz, R., F. J. Rauscher III, C. Abate, and T. Curran. 1989. Parallel association of fos and jun leucine zippers juxtaposes DNA binding domains. Science 243:1695-1699.

19. Gewirtz, A. M., and B. Calabretta. 1988. A c-myb antisense oligodeoxynucleotide inhibits normal human hematopoiesis in vitro. Science 242:1303-1306.

20. Gillis, S., and K. A. Smith. 1977. Long-term culture of tumorspecific cytotoxic $T$ cells. Nature (London) 268:154-156.

21. Gorman, C. M., L. F. Moffat, and B. H. Howard. 1982. Recombinant genomes which express chloramphenicol acetyltransferase in mammalian cells. Mol. Cell. Biol. 2:1044-1051.

22. Graf, T., and H. Beug. 1978. Avian leukemia viruses: interaction with their target cells in vivo and in vitro. Biochim. Biophys. Acta 516:269-299.

23. Gunning, P., P. Ponte, H. Okayama, J. Enger, H. Blaw, and L. Kedes. 1983. Isolation and characterization of full-length cDNA clones for human alpha-, beta-, and gamma-actin mRNAs. Skeletal but not cytoplasmic actins have an amino-terminal cysteine that is subsequently removed. Mol. Cell. Biol. 3:787795.

24. Ishikura, H., Y. Honma, C. Honma, M. Hozumi, J. D. Black, T. Kieber-Emmons, and A. Bloch. 1987. Inhibition of messenger RNA transcriptional activity in ML-1 human myeloblastic leukemia cell nuclei by antiserum to a $c-m y b$-specific peptide. Cancer Res. 47:1052-1057.

25. Katzen, A. L., T. B. Kornberg, and J. M. Bishop. 1985. Isolation of the proto-oncogene c-myb from $D$. melanogaster. Cell 41: 449-456.

26. Kelly, K., B. H. Cochran, C. D. Stiles, and P. Leder. 1983. Cell-specific regulation of the c-myc gene by lymphocyte mitogens and platelet-derived growth factor. Cell 35:603-610.

27. Kingston, R. E., A. S. Baldwin, and P. A. Sharp. 1984. Regulation of heat shock protein 70 gene expression by c-myc. Nature (London) 312:280-282.

28. Klempnauer, K.-H. 1988. Interaction of myb proteins with nuclear matrix in vitro. Oncogene 2:545-551.

29. Klempnauer, K.-H., H. Arnold, and H. Biedenkapp. 1989. Activation of transcription by $v$-myb: evidence for two different mechanisms. Genes Dev. 3:1582-1589.

30. Klempnauer, K.-H., T. J. Gonda, and J. M. Bishop. 1982 Nucleotide sequence of the retroviral leukemia gene v-myb and its cellular progenitor c-myb: the architecture of a transduced oncogene. Cell 31:453-463.

31. Klempnauer, K.-H., and A. E. Sippel. 1987. The highly conserved amino-terminal region of the protein encoded by the $\mathrm{v}-m y b$ oncogene functions as a DNA-binding domain. EMBO J. 6:2719-2725.

32. Ledbetter, J. A., and L. A. Herzenberg. 1979. Xenogenic monoclonal antibodies to mouse lymphoid differentiation antigen. Immunol. Rev. 47:63-90.

33. Lipsick, J. S., and W. J. Boyle. 1987. c-myb expression is a late event during T-lymphocyte activation. Mol. Cell. Biol. 7:33583360 .

34. Malek, T. R., R. J. Ribb, and E. M. Shevach. 1983. Identification and initial characterization of a rat monoclonal antibody reactive with the murine interleukin 2 receptor-ligand complex. Proc. Natl. Acad. Sci. USA 80:5694-5698.

35. Morse, H. C., III, W. F. Davidson, R. A. Yetter, E. D. Murphy, J. B. Roths, and R. L. Coffman. 1982. Abnormalities induced by the mutant gene lpr: expansion of a unique lymphocyte subset. J. Immunol. 129:2612-2615.

36. Mountz, J. D., A. D. Steinberg, D. M. Klinman, H. R. Smith, and J. F. Mushinski. 1984. Autoimmunity and increased c-myb transcription. Science 226:1087-1089.

37. Mushinski, J. F., M. Potter, S. Bauer, and E. P. Reddy. 1983.
DNA rearrangement and altered RNA expression of the c-myb oncogene in mouse plasmacytoid lymphosarcomas. Science 220:795-798.

38. Nishiha, Y., H. Nakagoshi, F. Imamoto, T. J. Gonda, and S. Ishii. 1989. Trans-activation by the c-myb proto-oncogene. Nucleic Acids Res. 17:107-117.

39. Onclercq, R., P. Gilardi, A. Lavenu, and C. Cremisi. 1988. c-myc products trans-activate the adenovirus E4 promoter in EC stem cells by using the same target sequence as E1A products. J. Virol. 62:4533-4537.

40. Pauza, C. D. 1987. Regulation of human T-lymphocyte gene expression by interleukin-2: immediate-response genes include the proto-oncogene c-myb. Mol. Cell. Biol. 7:342-348.

41. Remmers, E. F., J. Q. Yang, and K. B. Marcu. 1986. A negative transcriptional control element located upstream of the murine c-myc gene. EMBO J. 5:899-904.

42. Setoyama, C., R. Frunzio, G. Liau, M. Mudryj, and B. de Crombrugghe. 1986. Transcriptional activation encoded by the v-fos gene. Proc. Natl. Acad. Sci. USA 83:3213-3217.

43. Sheiness, D., and M. Gardinier. 1984. Expression of a protooncogene (proto- $m y b$ ) in hematopoietic tissues of mice. Mol. Cell. Biol. 4:1206-1212.

44. Shen-Ong, G. L. C., H. C. Morse III, M. Potter, and S. Mushinski. 1986. Two modes of c-myb activation in virusinduced mouse myeloid tumors. Mol. Cell. Biol. 6:380-392.

45. Sherman, P. A., P. V. Basta, T. L. Moore, A. M. Brown, and J. P.-Y. Ting. 1989. Class II box consensus sequences in the HLA-DRA gene: transcriptional function and interaction with nuclear proteins. Mol. Cell. Biol. 9:50-56.

46. Shipp, M. A., and E. L. Reinherz. 1987. Differential expression of nuclear proto-oncogenes in T cells triggered with mitogenic and nonmitogenic T3 and T11 activation signals. J. Immunol. 139:2143-2148.

47. Slamon, D. J., T. C. Boone, D. C. Murdock, D. E. Keith, M. F. Press, R. A. Larson, and L. M. Souza. 1986. Studies of the human c- $m y b$ gene and its product in human acute leukemias. Science 233:347-351.

48. Southern, P. J., and P. Berg. 1982. Transformation of mammalian cells to antibiotic resistance with a bacterial gene under control of the SV40 early region promoter. J. Mol. Appl. Genet. 1:327-341.

49. Stern, J. B., and K. A. Smith. 1986. Interleukin-2 induction of $\mathrm{T}$-cell $\mathrm{G}_{1}$ progression and c-myb expression. Science 233:203206.

50. Thompson, C. B., P. B. Challoner, P. E. Neiman, and M. Groudine. 1986. Expression of the c-myb proto-oncogene during cellular proliferation. Nature (London) 319:374-380

51. Torelli, G., L. Selleri, A. Donelli, S. Ferrari, G. Emilia, D. Venturelli, L. Moretti, and U. Torelli. 1985. Activation of c-myb expression by phytohemagglutinin stimulation in normal human T lymphocytes. Mol. Cell. Biol. 5:2874-2877.

52. Torelli, G., D. Venturelli, A. Colo, C. Zanni, L. Selleri, L. Moretti, B. Calabretta, and U. Torelli. 1987. Expression of c-myb protooncogene and other cell cycle-related genes in normal and neoplastic human colonic mucosa. Cancer Res. 47:5266-5269.

53. Turner, R., and R. Tjian. 1989. Leucine repeats and an adjacent DNA binding domain mediate the formation of functional cFoscJun heterodimers. Science 243:1689-1694.

54. Weston, K., and J. M. Bishop. 1989. Transcriptional activation by the v-myb oncogene and its cellular progenitor, c- $m y b$. Cell 58:85-93.

55. White, B. A., and F. C. Bancroft. 1982. Cytoplasmic dot hybridization. Simple analysis of relative mRNA levels in multiple small cell or tissue samples. J. Biol. Chem. 257:85698572.

56. Yokota, S., D. Yuan, T. Katagiri, R. A. Eisenberg, P. L. Cohen, and J. P.-Y. Ting. 1987. The expression and regulation of c-myb transcription in B6/lpr Lyt-2- ${ }^{-}$L3T4- ${ }^{-}$lymphocytes. J. Immunol. 139:2810-2817. 